\title{
Managing risk in complex adult professional learning: the facilitator's role
}

\begin{abstract}
This paper reports on the recognition and management of risk within the context of an intensive literacy intervention professional development programme, designed to enable expert literacy teachers become teacher-educators. The paper suggests a conceptual model for recognising risk within professional learning opportunities and skills for facilitators. Data was generated from digital audio recordings of professional development sessions and semi-structured interviews. Data were analysed using a grounded theory approach. Data analysis revealed attributes for facilitators which enabled or determined their ability to manage risk. Extracts from transcripts illustrate the nature of risk and participant perception. Implications for facilitators of professional learning to support learners through their transformative learning journey are discussed.
\end{abstract}

Keywords: teacher professional development; risk; cognitive dissonance; transformative learning, facilitator.

\section{Introduction}

Engaging in a year-long professional development programme for experienced and expert literacy professionals implies a willingness to develop and to change one's practice. But change and more specifically, transformation requires risk (Darling-Hammond and McLaughlin, 1995; Ono et al. 2011). This appears to create a tension that affects adult learners particularly (Argyris and Schön, 1974) since it seems that when they choose further study they come as successful expert teachers with little, if any, experience of professional failure and understanding of the potential risks associated with transformative learning (Mezirow, 2009). Teachers commencing professional learning programmes are putting themselves in a learner situation and potentially a risk taking position. There are potential risks associated with being an adult learner; being a student, submitting work, attending lectures, contributing to discussions and completing a Masters award. Learners also risk failure in the teacher-educator role by not being able to move 
from their current construct of early literacy teaching and learning and into the role of a teachereducator and the specific responsibilities and facilitation of adult learning that this requires. The risk is both professional and personal.

This paper reports on the recognition and management of risk within the context of an international intensive literacy intervention professional development programme implemented in Australia, Canada, Denmark, Ireland, New Zealand, USA and the UK (Watson and Askew, 2009). The programme is designed to enable experienced teachers become expert literacy

teachers and expert literacy teachers become teacher-educators. It offers observable examples of the complexity of adult professional learning through its use of observed live lessons via a oneway screen and led by a facilitator.

The study explored how facilitators of complex professional learning, in whatever field of study, might have greater understanding of how they can recognise and effectively manage potential risks within professional learning programmes.

\section{Context}

Taking a successful professional development model (Guskey, 2000) and transferring it to different cultures, settings can be problematic (Watson and Askew, 2009). This research focuses on a professional development programme which adopts a social constructivist approach and is predicated on a commitment for participants to engage in ongoing professional development whilst they remain in role as specialist teachers of a literacy intervention (Burroughs-Lange and author, 2012). It is a Masters level professional development programme which offers layers of development. These range from the initial training of experienced teachers as specialist early literacy teachers (IPD), through continuing professional development (CPD), to Teacher Leaders working at Masters level to become teacher- educators, facilitating IPD and CPD.

Cognitive dissonance, defined in this study as an inconsistency in cognition and antecedent condition leading to activity to reduce dissonance (Festinger,1957) is explicitly discussed within the professional development model (Burroughs-Lange and author, 2012). It is also experienced by participants in planned and unplanned incidences leading to increased risk for learning if facilitators are unable to recognise, identify and manage cognitive dissonance as an educative resource and associated risks. This professional development programme provides an observable example of the complexity of adult professional learning through its use of observed live lessons via a one-way screen led by a facilitator (Figure 1). The professional development programme 
follows a similar format regardless of location or facilitator for each session: introduction and theoretical focus, two live lessons observed via a one-way screen observed and critiqued led by facilitator, discussion and links to theory and readings. Insert figure 1

\section{The role of the facilitator}

The role of the facilitator is a crucial one in complex adult professional learning. A facilitator may be interpreted as someone who makes it easy for something to happen or who eases the way for someone. In some respects that is helpful; the role of facilitator often involves taking certain responsibilities on board to relieve the learner so that they can concentrate on what is important in the learning. The possible danger is that the learner becomes passive and relies upon the facilitator to make the links, provide the understanding as well as the context, resources and opportunities. An alternative is the concept of an informed guide. One that helps to create the learning environment but is not in charge, and rather fosters a sense of a learning community (Wenger, 1998) enabling learners to take responsibility for their own actions, understandings and change. But within the complex world of adult professional learning there are clear roles and responsibilities. Baviskar, Hartle, and Whitney, (2009) offer four criteria as prompts from a constructivist approach for discussing the facilitator role: eliciting prior knowledge, creating cognitive dissonance, application of the knowledge with feedback and reflection on learning. Critical reflection appears to be a routine part of many current programmes of study across a range of disciplines, manifested in the writing of journals, e-journals and particular approaches and tasks (Cranton, 1996; Boud, 1995; Williams, 2001). It is the role of the facilitator to introduce these reflective opportunities and to enable the learners to gain from these opportunities. Brookfield expresses the role as 'to present to them ideas and behaviours that cause them to examine critically their values, ways of acting and the assumptions by which they live (1986: 23).

From a practical perspective this might be interpreted and implemented through critical questioning, as a process for resolving learning dissonance, and the use of critical incidents as foci for discussion, possibly supported by the use of reflective journals (Williams, 2001; Hodge and Chandler, 2010). However, as Day (1993) suggested it seems that opportunities for reflection and being asked to reflect may not always lead to the critical reflection at the necessary level and depth for change to occur, suggesting that there is something within the role of the facilitator that 
enables some to manage this process effectively and for deep learning (Biggs, 1999) to occur. Cranton suggests the facilitator:

...responds to the needs of the learners, fosters a meaningful group process, provides support and encouragement, builds a trusting relationship with learners, helps challenge peoples' assumptions and beliefs, and accepts and respects learners (2006:105).

This recognition of the challenge of previously held beliefs and assumptions echoes Brookfield (1987) and extends the constructivist concept of eliciting prior knowledge. It is important as part of valuing the learner's previous experience and contribution but goes further through the 'surfacing and animating' of knowledge and understanding (Perkins, 2006: 40) which then enables challenge. Mezirow (1991) argues for the importance of challenging our assumptions at two levels. First, the re- examination of previously held views as part of the process of transforming meaning schemes, which he states as integral to the process of reflection and the dynamics of reflective learning. Second, the possibility of finding our basic premises challenged through a 'disorientating dilemma' (1991:192) which may lead to major changes in how we view the world and thus engender perspective transformation. For assumptions and beliefs to be challenged either personally or by others, a situation that offers alternatives in approach, belief, or perspective together with a supportive environment is required (Brookfield, 1986).

Being able to move beyond what might be perceived as personal criticism of an individual into the principles underpinning the behaviours, views, and understandings may be difficult, especially for experienced professionals. There is potential for the personal investment by the individual in the learning experience to cloud their ability to differentiate between Brookfield's 'personal denigration' (1986, p.13) and constructive criticism (Ono et al. 2011). The opportunity to have meaningful feedback directly related to the needs of the professional and their future growth relies upon the pedagogy of the programme and tutor facilitation. The 'critical friend' (Lyons, Pinnell, and DeFord, 1993) is a powerful model and one which Osterman and Kottkamp express as 'the facilitator is not a superior assessing performance quality but a collaborator stimulating professional growth in a way consistent with the needs of the individual' (1993:179). Collaborative learning offers both the opportunity for professional growth, and supports the development of self-concept in the learners. It suggests a constructivist approach to learning whereby: 
Collaborative groups are important because we can test our own understanding and examine the understanding of others as a mechanism for enriching, interweaving and expanding our understanding of particular issues or phenomena (Savery and Duffy, 1995: 2).

The influence of collaborative working and the power of creating our own truths, constructed from shared understandings place a responsibility upon the facilitator so that within the learning environment members are able to discuss, challenge and contemplate their own constructs and the observable tensions that might arise from shared experiences within the group. According to Argyris and Schön (1974) there are opportunities for facilitators to support learning through both congruence between values and behaviours, leading to unexpected consequences, and incongruence between theories in use and espoused theories. This notion of congruence echoes with another role for the facilitator. In research on study orchestration and dissonance (Prosser, Ramsden, Trigwell and Martin, 2003) congruence between the facilitator's beliefs and delivery had an impact upon student outcomes with deep learning occurring with congruence. This seems to suggest that the facilitator also needs to consider whether the methods, approaches and tasks they use are congruent with the outcomes they plan for their students. Further, studies by Cano (2005); Wisker, Robinson, Trafford, Creighton, Warnes (2003); Boulton-Lewis et al (2003); Long (2003) suggest that congruence between the students' expectations, learning style, and that of the learning experience or programme pedagogy is required. Potentially this places a burden upon the facilitator. They need to be aware of the source and nature of any incongruities, selfaware of their own perspectives, familiar with the curriculum and pedagogy of the programme so that they can flexibly and creatively meet the needs of the learners whilst simultaneously creating the greatest opportunities for the students to learn (Baviskar, Hartle, and Whitney, 2009). However, the responsibility is not solely that of the facilitator. As Perkins (2006) makes clear both parties have choices within the learning process and to engage in cognitively demanding challenges may not be attractive for all learners. A pragmatic approach to constructivism suggests the facilitator creates a learning environment such that incongruities and possible sources of dissonance are managed so that they become learning opportunities not barriers to progress or as Perkins suggests: 'The best constructivist teaching becomes an art of intellectual seduction, luring students into learning in ways deeper than those to which they might be disposed' (2006: 45). Throughout literature the role of facilitator is recognised as complex and 
demanding, but common responsibilities towards the learner, pedagogy and curriculum goals of the programme are also identified.

\section{The study}

The research was designed as an exploratory multiple case study. Each case was one professional development (PD) session at a centre which included two literacy intervention lessons observed through a one-way mirror, known as the 'screen' (Figure 2). The focus for each case was behind the screen observation and critique of live lessons as an example of complex adult professional learning. In that distinct environment, teacher-educators led a group of early literacy teachers, either in their training year (IPD), or subsequently in continuing professional development (CPD) to critique the teaching interactions as they occur behind the screen with the aim of generating hypotheses. As part of that process cognitive dissonance is explicitly introduced to facilitators in their training as an educative resource for working behind the screen. They then introduce it explicitly to their teachers but cognitive dissonance may also occur naturally within professional development (Ince, 2015). The location and context of the actual physical set up; high stools or chairs looking through a viewing screen into a small teaching room, is the same in each PD centre (RRNN, 2006). This provides a consistency of physical environment for the data collection and observations. It also enables the focus to be on the learning that this physical environment supported. Insert figure 2

Each participant was a teacher-educator or tutor (referred to as a facilitator in this paper) who gave permission for their groups of teachers (IPD, CPD) or teacher-educators in training (facilitators in training on the professional masters) to be approached to consent to the professional development session being included within the study. Participant facilitators were drawn from across the range of professional development sessions run across the UK, rural to urban, newly qualified to experienced. Each centre where the facilitator/s were based was assigned a pseudonym, Avalon, Balmoral, Camelot and Duchy. All PD sessions were based on a 
social constructivist approach and followed the session format as outlined previously. Table 1 shows the sampling strategy and participants after Morse (2007). Insert table 1.

\section{Data collection}

Multiple sources of data were adopted to reduce the possibility of bias, to aid triangulation and to create a 'chain of evidence' (Yin, 2009:122). Data were collected through naturalistic audio taped observations, field notes, including handouts from the professional development sessions and semi-structured interviews. A key element was the audio taping using a hand held digital recorder of the facilitator (teacher-educator) enabling discussion and critical hypothesising by the observing teachers of the teaching interactions occurring behind the screen. These audio-taped sessions were transcribed and sent as both audio recordings and hard copy to the facilitators for member checking. Semi-structured interviews with facilitators and facilitators in training were digitally recorded, transcribed and shared with them. Ethical approval was sought and given. All names have been changed for confidentiality and written permission given for the use of figure 1 photograph. In addition, consent was obtained from children and teachers whose lessons were observed via the screen within the PD sessions.

\section{Data analysis}

This study adopted a grounded theory (Glaser and Strauss, 1999) approach to data analysis. As data were collected analysis started simultaneously. Categories and themes emerged from the data. A constant comparison method was applied creating a tight loop of coding, reviewing, revisiting data sources. A research journal captured the process and informed memos. NVivo software was used for coding and the journal for memos and conceptual relationships. Key themes emerged around identification of features or characteristics of cognitive dissonance and the role of the facilitator. A complex relationship emerged between cognitive dissonance, the use of observation and the role of the facilitator mediated by change over time which led to the development of a skeleton conceptual framework as an expression of this relationship.

\section{The risk area}

Data analysis suggested that there was a complex relationship between the role of the facilitator and their knowledge and understanding of cognitive dissonance in learners. This led to a distinct risk area created within professional development sessions linked explicitly to cognitive 
dissonance. This risk area changed over time, although it was not hierarchical or linear. Rather, learners (teachers attending either IPD or CPD sessions, and facilitators in training on the professional masters) moved between and across as their personal learning journey progressed (Figure 3).

There is a risk that the facilitator misses opportunities to support learning and that learners experience cognitive dissonance in such a way that they reject learning opportunities or in extreme cases reject the whole experience (Cano, 2005; Galman, 2009). This risk area is created when the facilitator is new to the role and does not engage deeply in critical reflection. When these factors are combined with lower personal commitment and motivation to become a skilled observer there is less understanding of cognitive dissonance. This results in the risk area where the facilitator is less likely to recognise cognitive dissonance as it occurs or to identify opportunities to introduce it in order to support transformative learning and trigger the shift from procedures towards conceptual understandings.

I think I picked up on procedural elements actually, rather than thinking about why they are doing it I noted down here speeding up the writing and how they would do that and again it going back to procedures rather than why they are doing it (Gemma, facilitator interview).

Within the risk area facilitators seem less observant and may miss the reactions, physical, emotional, of their learners as they react individually and personally to a challenge to their knowledge construct. It may be that newly qualified facilitators focus on their own performance and the challenge of facilitating reduces their observational capacity? Or perhaps they are observing so closely the teacher child interactions behind the screen, they may miss the reactions of the learners observing with them? Inability to recognise cognitive dissonance means that its potential power as an educative resource cannot be harnessed for perspective transformation leading ultimately to new learning. If the facilitator is unaware of the learners' discomfort, created by cognitive dissonance, then they are not in a position to support the learner to work through the challenge by engaging in cycles of critical reflection where they can tussle with their understanding and challenges to it. This engagement in cycles of critical reflection is important in reducing the learners' feeling of discomfort from a cognitively dissonant experience and in supporting them to resolve the cognitive conflict (Festinger, 1957; Ince, 2010). Lack of awareness by the facilitator may also create inadvertent cognitive dissonance whereby the facilitator sets expectations that are at odds with the position of the learner or group on their 
learning journey (Postareff, Katajavuori, Lindblom-Ylianne, and Trigwell, 2008). Sarah identified an example of this in her own facilitation:

I started re-listening to this session, I'd not included myself and I re-listened and thought well actually perhaps I do need to include myself because actually there are times when an action of mine has created some dissonance (Sarah, facilitator interview).

The risk seemed to be heightened within the lower zones of risk and as experience and observational skill increased, this lessened, Figure 3 represents this diminishing risk by fading out the potential jeopardy area. Alternatively, learners experiencing too much cognitive dissonance which they are unable to accommodate within their 'theory in use' (Argyris and Schön, 1974) leads them to deny and reject new learning (Galman, 2009; Ince, 2010). The difficulty in recognising cognitive dissonance constrains the facilitator's ability to support the group in building cycles of talk that develop their understanding and to assist to problem solve the challenges created by the cognitive dissonance. Insert figure 3

A further dimension to the risk area was identified by facilitators in the study. They explicitly discussed the risk involved in introducing cognitive dissonance to learners. There were two distinct parts to their concerns. The first concern was that it seemed counter intuitive to introduce something to learners which would challenge their existing understandings and make them feel uncomfortable. This was raised in a variety of ways across the majority of interviews. Gemma focussed on her anxiety of challenge being construed as negativity:

I don't want the group to see it as me being negative or critical in negative way of what they are doing (Gemma, facilitator interview).

Whereas Andrea reflected on the tension between how she wanted to be viewed by the group as a kind, nice person who they could be friends with and her role in supporting their learning throughout an intensive professional development year:

There's that tension between I want to be kind really to the person who's doing the lesson for us and the fact that they really do need to move on and they need to understand that you have to... (Facilitator interview).

This concern over the potential for making learners feel uncomfortable seems valid when considered against the facilitators' key role in developing a safe environment where learners felt secure and could take risks: 
it needs to be made into a safe environment doesn't it where you can say or see you can speak and even if what you say doesn't turn out to be relevant or isn't taken on in discussion it's ok for you to have said that it's not embarrassing no one should walk away cringing (Amelia, facilitator interview).

It seems that some facilitators were still tussling with finding the balance between opportunities

for discussing misunderstandings with colleagues in a depersonalised and productive manner and being able to move beyond their comfort zone.

I think partly the group because, we are a culture of learning and it's ok to, maybe, to have had a misunderstanding, because to be able to talk it through with other people who would come in and, and say "yeah, I've done this", and perhaps the realisation that actually it wasn't the end of the world either, I hadn't stopped those children learning (Amelia, facilitator interview).

Others seemed to recognise the need for an environment where learners felt safe to take risks and step towards the 'edge of knowing' (Taylor, 2009:10).

The second aspect to their concern over the use of cognitive dissonance was that it created risk for them as professionals.

There's that perception that if you've had cognitive dissonance if you are trying to grapple with your understanding, that's not very professional (Pamela, facilitator interview).

This concern appeared to centre on their previous experiences of professional development and understanding of the facilitator role. More experienced facilitators were aware of the risks associated with introducing cognitive dissonance to their learners and the potential discomfort it might create. They were less likely to be concerned over external perceptions about the nature of professional learning and the risk to their status as professionals. Instead they saw resolution of cognitive dissonance as an important part of the learning process.

\section{The complex role of the facilitator in managing risk}

Facilitating adult professional development is complex. The facilitator needs to enable their learners to progress from learning about procedures (what to do and when) to behaviours (the 'how to' as applied to the particular context e.g: teaching, observing, giving and receiving feedback, critique), and then to deeper understanding of key concepts (the why). Underpinning 
this progression is the facilitator's own understanding of potential risk. If the facilitator does not recognise or is less able to identify risks for learners opportunities are lost and the risk area increases, i.e.: missed opportunities for learning, potential overload through too much cognitive dissonance (Galman, 2009). The facilitator needs to identify how to support the learners' progression through the zones whilst also enabling a shift from responsibility for the learning environment and learning opportunities from the facilitator to the learners themselves. This change over time in responsibility is an important goal for the facilitator role. Figure 4 shows how the continuum of skill and change over time might be represented. Insert figure 4

Interpretation of data suggested five factors that appeared to affect the success of the facilitator role in enabling this progression. These were: the ability to critically reflect, experience in role, acuity of observation, personal motivation or commitment and knowledge and understanding of cognitive dissonance in learning. Although, congruence featured in literature and seemed a likely explanation, it was not identified within the data. Each of the five factors seemed to predicate the position of the facilitator on a continuum of complex skill development shown in figure 4 . The continuum ranged from least skilled to most skilled, with data suggesting that combinations of factors might promote or inhibit progress along that continuum and that it ebbed and flowed. For example; it seemed that factors of acuity of observation affected procedures, behaviours and learners, whilst the ability to critically reflect on their own practice and observed practice supported the shift in focus from lesson towards the ability to use whatever was observed to meet the needs of learners. Experience and personal motivation or commitment appeared to directly affect the facilitator's ability to engage with and develop the other factors involved in moving through the continuum of skill.

Experience: It would seem reasonable to suppose that increased experience as a facilitator would positively impact upon one's position along the continuum of skill. Certainly lack of experience impacted upon the likelihood of working in the risk area. Experience was an important factor in the facilitators' ability to provide an appropriate learning environment, to manage the group dynamic, and to shift from procedures to behaviours, supporting their learners move through the zones of cognitive dissonance. The experience included both longevity in role and the richness of experience in terms of the learning environment (Taylor, 1998).

It was perceived by the facilitators themselves as a factor which impacted on their performance. 
that's the highest we have ever been and I think, you know, that is no doubt because I'm more experienced, the teachers have had a much better year this year than they had last year, but actually for those experienced teachers things are coming together (Laura, facilitator interview).

Data analysis highlighted a tension between the perceived benefit of experience by participants and the profiles. Experience in role was useful as it enabled the facilitator with organisational and pragmatic aspects of the learning environment, managing group dynamics and subject knowledge. However, in some circumstances it could act as a barrier:

and I think there is a pattern there because the more somebody's done, you know, unless they are willing to have that really open mind, it's got to get in the way you know, (Andrea, facilitator interview).

Lack of experience in role potentially hindered facilitators in their interactions with the group but more importantly with supporting the shifts from zones one and two into thinking more deeply increasing the likelihood of working within the risk area:

I think that I talk for too much and I think sometimes their silence makes me talk instead of waiting or I don't know, I haven't quite worked out how to - get more from them (Gemma, facilitator interview).

Less experienced facilitators were challenged in managing their own experiences of cognitive dissonance. For example: actually identifying dissonance itself appeared more difficult for less experienced facilitators whilst the potential for creating inadvertent dissonance seemed greater. An experience which is dissonant for the learners may also be dissonant for the facilitator. That may affect their ability to support the group in managing that experience in a way that utilises cognitive dissonance to move the learners forward rather than intensifying the risk to learners of disengagement and overload.

So I thought that maybe I'd got it completely wrong or that I wasn't actually sort of going deep enough so that they would get that lift and think about the purpose and how to get the children to move on so I think I was looking for the wrong thing (Gemma, facilitator interview).

Data enabled individual participant facilitator profiles to be developed against the five factors. Figure 5 uses a radar diagram to show the individual profiles for three participants. Positions further from the centre indicate higher levels of the identified factors. So whilst Gemma was less experienced than both Laura and Andrea she was more motivated. 
Analysis of data showed that although experience was felt to be important by facilitators it was not sufficient on its own to enable the progression towards deeper understanding at a conceptual level. It could be that experience in role was less important in determining a facilitator's skill than the abilities to observe, critically reflect, to have knowledge and understanding of cognitive dissonance and their personal motivation or commitment as facilitators. Insert figure 5

\section{A risky business: the learning environment in complex professional learning}

At the heart of the professional development programme for this study was a learning environment which actively engaged all participants with clear expectations that they would share their observations and insights in real time for the benefit of all. Facilitators' mediation of learning through discussion and the decisions they make are inseparable from the climate for learning they engender or as Brown states:

For educators this means that the learning environment is not simply the location of learning, as widely construed, but the set of conditions that enable and constrain learning (Brown, 2009, p.5).

In selecting this PD programme with its standardised layout and structure (figure 2), a conscious decision was made that any emergent focus on the learning environment whilst acknowledging the physical set up, would be on the climate for learning. This has echoes with Roskos and Bain (1998) and their focus on identifying features that supported professional development in learning environments. Whilst Brown (2009) proposed that:

the learning environment should be structured so that it best enables particular learning of knowledge, skills, attitudes and values, that constraints to this are minimised or absented, and that other learning is constrained (p.30-1).

Facilitators are key in how this is achieved. From previous discussion it seems that risk is important. There are the risk areas for learners created in part by lack of skilled facilitation. But perhaps more fundamentally, learners need to take risks in 'surfacing and animating' (Perkins, 
2006: 40). Creating a climate for learning that supports risk taking appears to be crucial for a social constructivist approach, as explicitly promoted by the professional development programme of this study, to successfully operate. The perceived risk by learners seems to centre on a risk to their personal and professional credibility by being 'wrong' in some way. Engaging with this was seen as a risky business by both facilitators and learners and one which required thought. Data suggested reluctance by learners to offer their views and facilitators interpreted this and took responsibility.

I would just like them to be able to say something and to share their ideas but I think they are a little, they seem a bit nervous sometimes it's about getting it wrong and you know I suppose that's you know they are still on that right and wrong which is possibly also coming from me (Gemma, facilitator interview).

The responsibility was two-fold. Facilitators wanted contributions so that assumptions and tacit knowledge could be brought to the surface and discussed (Perkins, 2006). So facilitators felt that it was their questioning or probing that was at fault if this did not occur. But they also recognised that creating a safe environment was important in order to get contributions.

I think it was done really well because I remember feeling very nervous about it that first time and feeling nervous then you encouraged us to take risks. Realised that actually it was okay to do that within a group nothing is going to go wrong if you start discussion that doesn't go anywhere you can change what you're talking about ( Pam, facilitator interview).

Facilitators reflected on things they had observed and models of how they as facilitators themselves might progress and enable change over time in their learners through the way in which they interacted:

I think it's also when you're aware that they are calling for you to do more. "Well done for your contributions last week, this time I want you to do this" and you begin to become aware of the complexity of what you are doing (Amelia, facilitator interview). 
First, facilitators positively valued contributions by learners to encourage them to continue to share observations and insights. Facilitators saw their role as encouraging but also setting clear expectations and supports and they drew on their personal experience of how this was done.

but it was scaffolded we all had a go and we had a group that we all trusted (Pam, facilitator interview)

we were told what we'd done well and then you set goals didn't we for what to do next time and what to focus on (Amelia, facilitator interview.)

These approaches to creating an environment that enabled risk taking, in the sense of sharing observations, insights and then alternative interpretations created a sense of community whereby participants felt able to acknowledge and admit to not knowing in a way which was counter intuitive to their previous experiences as education experts:

but it's still not about knowing the answers to everything and actually it's as ok now as it was at beginning of year to say I don't know let's have a look and examine what's going on, what do you think is going on? (Susan, facilitator interview).

That safety in belonging to a community was crucial for the learners if the facilitators were to make the shift to provoking responses by playing devil's advocate and using cognitive dissonance as an educative resource. Sarah reflected that once her group were risk takers she could exploit dissonance to move her learners forward.

The group had become risk takers and happy to challenge..... And so I think it was me that was calling for some constructive support for the teacher and ways of supporting the teacher to take the child forward so that all came from that ..beginning where there seemed to be some dissonance between what the teacher had said about the child and what the group were noticing (Sarah, facilitator interview).

Key components for a climate for learning emerged. The first of these was the crucial role of the facilitator in modelling how to behave within that environment. The behaviours expected included observing and articulating or listening simultaneously, contributing in a constructive, positive and tentative manner. With the expectations of behaviour and contributions came the safety of being part of a community that enabled risk taking. 
Because as a group somebody comes up with something and then if they are able to vocalise it in the group it's ok (centre Duchy).

These feelings of community and shared experience resonate with Mezirow's stage 4 of perspective transformation (2009: 94) whereby there is an element of risk and sense of a loss of control. Professionals do encounter risk to their personal identity and knowledge constructs when they embark on new learning and being able to let go of previously held firm beliefs within a supportive community seems to make it a slightly easier process, as does sharing the experience and seeing others in a similar situation.

I think it's great but because of the context in which it happens is really supportive which is important and because we all know are all going through it and we are all at different stages of understanding different aspects (Pam, facilitator interview).

The environment was not just about the facilitator. There was a need for the learners to engage too. This need is affected by a range of factors. Perkins (2006) identifies learners' personal approaches as important within a constructivist approach. He identifies the challenges of cognitive demands which not every learner is comfortable in assuming. These challenges impact on the learners' level of engagement, systematic and deep or superficial and less systematic with outcomes to match. Other studies on cognitive dissonance identify engagement as key. They investigate relationships between student expectations and understandings of learning and factors which make this consonant or dissonant and the resultant outcomes (Cano, 2005; Brindley, Quinn and Morton, 2008). From these studies it seems that learner engagement is important and operates at several levels. On one hand there is the basic engagement with the professional development programme, to turn up and participate. But beyond this level of engagement there can be dissonance between learner expectations and the learning environment (Postareff, Katajavuori, Lindblöm-Yliänne and Trigwell, 2008), the teaching approach and their preferred study approach (Vermunt and Verloop, 1999). In this PD programme teachers at every level had made a choice to participate and the 'behind screen' learning environment was new to all but the moral imperative (Fullan, 2004), acted positively on their commitment as they all wanted to improve the literacy of young children and saw this professional development as the opportunity to do so. However, a constructivist approach to teaching was not necessarily their expectation 
and was 'a different system' (Amelia, facilitator interview) to the characteristic didactic short courses experienced by participants (Bangs, Macbeath, Galton, 2011).

\section{Conclusion}

Whilst this study involved a particular learning environment the actual interactions and facilitation observed and recorded suggest that the findings have potential for other programmes. Facilitators operate as acute observers, critically reflective, skilled professionals able to enable others to become critically reflective, acute observers for themselves, whilst keeping a clear oversight of the learning journey and each individual's progress. Simultaneously, facilitators need secure subject knowledge, good pedagogy including a constructivist approach to adult learning (in this context). Furthermore, they need to be able to manage contributions skilfully as a tool for learning and as a motivator. This requires making moment by moment superb decisions (Clay, 2005) about whether to let things drop or to pick them up provoking responses and engagement to manage risk for the benefits of learners. These facilitation skills and requirements are not limited to the programme in this study, but are recognisable within many professional development contexts. Figure 6 proposes a model of how facilitators might respond to interactions or observed incidences within professional development sessions. Insert figure 6.

Thus, 'educators assist learners to bring this process into awareness and to improve the learners' ability and inclination to engage in transformative learning' (Mezirow, 2009: 94). The complexity of role operates in a symbiotic relationship with the learning environment which according to Schugurensky:

This brings us full circle back to transformative learning theory, which contends that transformative learning requires supportive relationships and a supportive environment that encourages a sense of personal efficacy, (2002: 71).

This has implications for the facilitator's personal awareness of their position on a continuum of facilitation skill and the factors that contribute. It suggests that whilst facilitators may implicitly acknowledge risk management within their role, a more explicit discussion of risk within complex professional learning may be helpful within facilitator professional development. Being free from anxiety and fear of failure liberates learners to engage in the cognitive processes towards new learning, the aim for all facilitators. 
References:

Argyris, C., Schon, D.A. (1974). Theory in Practice Increasing Professional Effectiveness. San Francisco, Jossey-Bass.

Bangs, J., MacBeath, J., Galton, (2011). Reinventing Schools, Reforming Teaching from political visions to classroom reality. Oxon: Routledge.

Baviskar, S., R. T. Hartle, et al. (2009). Essential Criteria to Characterize Constructivist Teaching: Derived from a review of the literature and applied to five constructivist-teaching method articles. International Journal of Science Education 31(4): 541-550.

Biggs, J. (1999). Teaching for Quality Learning at University. Buckingham, SRHE \& Open University Press.

Boulton-Lewis, G. M., L. Wilss, et al. (2003). Dissonance between Conceptions of Learning and Ways of Learning for Indigenous Australian University Students. Studies in Higher Education 28(1): 79-89.

Boud, D. (2001). Using Journal Writing to Enhance Reflective Practice. New Directions for Adult and Continuing Education 90(Summer 2001): 9-18.

Brindley, R., Quinn, S. M. F., Morton, M. L., (2009). Consonance and dissonance in a study abroad program as a catalyst for professional development of pre-service teachers. Teaching and Teacher Education, 25 (3), 525-532.

Brookfield, S. (1986). Understanding and Facilitating Adult Learning. San Francisco, JosseyBass.

Brookfield, S. (1987). Developing Critical Thinkers challenging Adults to Explore Alternate Ways of Thinking and Acting. Buckingham, Open University Press.

Brown, G. (2009). The Ontological Turn in Education The Place of the Learning Environment. Journal of Critical Realism 8(1): 5-34.

Burroughs-Lange, S. and author., Eds. (2012). Reading Recovery and Every Child a Reader: History, policy and practice. London, IOE Press.

Cano, F. (2005). Consonance and Dissonance in Students' Learning Experience. Learning and Instruction 15(3): 201-223.

Cranton, P. (1996). Professional Development as Transformative Learning new perspectives for teachers of adults. San Francisco, Jossey-Bass.

Cranton, P. (2006). Understanding and Promoting Transformative Learning a guide for educators of adults. San Francisco, Jossey-Bass. 
Darling-Hammond, L. and M. W. MacLaughlin (1995). Policies that support professional development in an era of reform. Phi Delta Kappen 92(6): 81-93.

Day, C. (1993). 'Reflection: a necessary but not sufficient condition for professional development'. British Educational Research Journal, 19 (1), 83-93.

Festinger, L. (1957). A Theory of Cognitive Dissonance. Stanford: Stanford University Press.

Fullan, M. and Ballew, A. (2004). Leading in a Culture of Change personal action guide and workbook. San Francisco: Jossey-Bass

Galman, S. (2009). Doth the lady protest too much? Pre-service teachers and the experience of dissonance as a catalyst for development. Teaching and Teacher Education 25(3): 468-481

Glaser, B. and A. Strauss (1999). The Discovery of Grounded Theory. New Brunswick, Aldine Transaction.

Guskey, T., (2000). Evaluating Professional Development. Thousand Oaks, Corwin Press Inc.

Hodge, N. And Chandler, S. (2010). It's not what you do; it's the way that you question: that's what gets results. Support for Learning, 25 (1), 11-14.

Ince, A . (2010) An exploration of cognitive dissonance in adult professional learning. Unpublished Institute Focussed Study. University of London, Institute of Education Doctor of Education Programme.

Ince, A. (2015) Managing risk in complex professional learning: the facilitator's role Paper presented at ECER, Budapest $8^{\text {th }}-12^{\text {th }}$ September 2015.

Long, W. F. (2003). Dissonance detected by cluster analysis of responses to the Approaches and Study Skills Inventory for Students. Studies in Higher Education 28(1): 21-35.

Lyons, C. A., Pinnell, G.S, DeFord, D.E, (1993). Partners in Learning Teachers and Children in Reading Recovery. New York, Teachers College Press.

Mezirow, J. (1991). Transformative Dimensions of Adult learning. San Fransico, Jossey-Bass.

Mezirow, J. (2009). An Overview of Transformative Learning. Contemporary Theories of Learning learning theorists in their own words. K. Illeris. Abingdon, Routledge: 90-105.

Morse.J. (2007). Sampling in Grounded Theory. The Sage Handbook of Grounded Theory. London, Sage.

Ono, Y., K. Chikamori, et al. (2011). Reflections on a mutual journey of discovery and growth based on a Japanese-South African collaboration. Professional Development in Education 37(3): 335-352.

Osterman, K. F., Kottkamp, R.B., (1993). Reflective Practice for Educators Improving Schooling Through Professional Development. Newbury Park, California, Corwin Press Inc. A Sage Publication Company. 
Perkins, D. (2006). Constructivism and troublesome knowledge. Overcoming Barriers to Student Understanding: Threshold Concepts and Troublesome Knowledge. J. H. F. Meyer and R. Land. Abingdon, Routledge Falmer: 33 -47.

Postareff, L., Katajavuori, N., Lindblom-Yliänne,S., Trigwell, K. (2008). Consonance and dissonance in descriptions of teaching of university teachers. Studies in Higher Education 33(1): 49-61.

Prosser, M., Ramsden, P., Trigwell, K. and Martin, E. (2003). Dissonance in Experience of Teaching and Its Relation to the Quality of Student Learning. Studies in Higher Education, 28 (1), 37-48.

Roskos, K. and R. Bain (1998). Professional Development as intellectual activity:Features of the learning environment and evidence of teacher's intellectual engagement. The Teacher Educator 34(2): 89-115.

RRNN (2006). Standards and Guidelines for the Implementation of Reading Recovery. London, Institute of Education.

Savery, J.R. and Duffy, T.T. (1994). Problem based learning: An instructional model and its constructivist framework. Educational Technology, 35, 31-38.

Schugurensky (2002). Transformative Learning and Transformative Politics: the Pedagogical Dimension of Participatory Democracy and Social Action. Expanding the Boundaries of Transformative Learning essays on theory and praxis. O'Sullivan, E.V., Morrell, A., and O'Connor, M.A., Basingstoke: Palgrave: 59-76.

Taylor, E. (2009). Fostering Transformative Learning insights from community, workplace, and Higher Education. In Mezirow, J., Taylor. E. And Associates Transformative Learning in Practice. San Francisco: Jossey-Bass.

Vermunt, J. and Verloop, N. (1999). Congruence and friction between learning and teaching, Learning and Instruction, 9, 257-280

Watson, B. and B. J. Askew, Eds. (2009). Boundless Horizons Marie Clay's search for the possible in children's literacy. Auckland, NZ, Heinemann.

Wenger, E. (1998). Communities of Practice: learning, meaning and identity. Cambridge: Cambridge University press.

Wisker, G. (2003). Recognising and overcoming dissonance in postgraduate student research. Studies in Higher Education 28(1): 91-105.

Yin, R. (2009). Case study research design and methods. Thousand Oaks: California, Sage 
